\title{
A Dicotomia da Alfabetização: Teoria Estadual versus Prática Escolar
}

Paulo Henrique Lohn Endereço Eletrônico: pauloh_lohn@hotmail.com

\section{INTRODUÇÃO}

Lecionar é comprometer-se com o outro, é dar o melhor de si para possibilitar um eficiente e eficaz aprendizado da criança que está em fase de aquisição de saberes. Dessa forma, educar é uma tarefa contínua, árdua às vezes, porém gratificante. Oportunizar àquele pequeno ser humano as condições básicas para alfabetizar-se, tornando-se um leitor e um escritor de seu próprio mundo, é maravilhoso. Todavia o desafio de ensinar a ler e escrever pode ser entendido como algo complexo ou até mesmo difícil, pois inúmeras são as teorias relacionadas ao tema da alfabetização e distintas são as realidades presentes nas escolas.

O Estado de Santa Catarina, por exemplo, possui sua própria Proposta Curricular, baseada nos Parâmetros Curriculares Nacionais. Tal documento tem a finalidade de direcionar a prática pedagógica nas unidades de ensino catarinenses, pois traz, em seu conteúdo, as concepções e métodos norteadores do processo de alfabetização no território barriga-verde, dentre outros assuntos. Em contrapartida, o que se observa como interessante é a ausência de sintonia, isto é, de relação entre as diretrizes teóricas catarinenses e a real prática evidenciada nas instituições educacionais estaduais.

Diante disto, buscou-se uma unidade de ensino estadual, situada no município de São Pedro de Alcântara para evidenciar qual método fundamenta as educadoras alfabetizadoras dessa escola, constatando a não ligação entre a teoria pregada pelo Estado de Santa Catarina e a realidade observada no estabelecimento em questão. Tais dados são os alicerces do estudo aqui desenvolvido. Além de também haver aqui o objetivo de demonstrar como, mesmo não seguindo determinada linha metodológica padrão, é possível alcançar êxito no processo de alfabetização.

Inicialmente, tomou-se como estratégia ressaltar o que é entendido por alfabetização e quais os três métodos essenciais aos processos de alfabetização. Em seguida, procurou-se compreender as 
teorias fundamentadoras da Proposta Curricular de Santa Catarina e, posteriormente, analisaram-se os dados obtidos na escola já mencionada. Concluindo, logo, o estudo objetivado.

\title{
2 DESENVOLVIMENTO
}

Etimologicamente, o vocábulo alfabetização refere-se à aquisição do alfabeto, isto é, desenvolver as habilidades de ler e escrever. Assim sendo, fundamenta-se na aprendizagem do sistema de escrita. Há diversos conceitos referentes à idéia de alfabetizar, sendo que estes devem estar embasados em perspectivas como: domínio de um código; ser capaz de ler expressões, textos produzidos por outras pessoas, compreendendo-os; ter conhecimento da leitura e da escrita como formas de comunicação, de interpretação e interação com o mundo.

Perante tais aspectos, a concepção de Magda Soares (1998, p. 33) encaixa-se adequadamente.

\begin{abstract}
Alfabetização é dar acesso ao mundo da leitura. Alfabetizar é propiciar condições para que o indivíduo - criança ou adulto - tenha acesso ao mundo da escrita, tornando-se capaz não só de ler e escrever, enquanto habilidades de decodificação e codificação do sistema da escrita, mas, e sobretudo, de fazer uso real e adequado da escrita com todas as funções que ela tem em nossa sociedade e também como instrumento na luta pela conquista da cidadania plena. (SOARES, 1998, p. 33).
\end{abstract}

As mudanças freqüentes que ocorrem na sociedade acabam por alterar as características do processo de alfabetização, pois em relação às modificações surgem novas necessidades. Um exemplo nítido pode ser identificado na realidade de que, até pouco tempo, sabendo decodificar a escrita para grande parte dos trabalhadores brasileiros era o fundamental. Em contrapartida, na atualidade, espera-se dos empregados uma apropriação maior do sistema de escrita, utilizando-o como um sistema de representação. Assim, a alfabetização deve ser entendida como um fenômeno social, nunca havendo possibilidade de ser efetuada isoladamente.

Segundo Ferreiro (2003, p. 28),

Alfabetização não é um estado, mas um processo. Ele tem início muito cedo e não termina nunca. Nós não somos igualmente alfabetizados para qualquer situação de uso da língua escrita. Temos mais facilidade para ler determinados textos e evitamos outros. O conceito também muda de acordo com as épocas, as culturas e a chegada da tecnologia.

Com influência notória decorrente das evoluções históricas, as maneiras de alfabetizar sofreram transformações. Logo, até a década de 1970, o foco brasileiro dizia respeito aos métodos de ensino que norteavam as escolas em relação aos seus educandos. Eram três os métodos: sintético, analítico e eclético. 
No primeiro, a aprendizado procede do simples para o complexo, partindo da letra para a sílaba, da sílaba para a palavra, da palavra para as frases e, finalmente, o texto completo. Já no segundo, parte de elementos significativos que conduzirão ao conhecimento dos elementos fonéticos, ou seja, parte de unidades maiores: a palavra, a oração, o conto, chegando aos elementos menores, como a sílaba e as letras. Enquanto o último caracteriza-se pela soma dos procedimentos e recursos utilizados nos métodos anteriores - sintético e analítico - sendo global, pois reúne elementos fonéticos apresentados de maneira significativa, por meio de uma história.

Com a publicação da teoria da psicogênese da escrita, houve um certo desinteresse para com os métodos e, em oposição, ocorreu um gigantesco investimento na pesquisa de processos de aprendizagem, interações em salas de alfabetização e outros assuntos similares. $\mathrm{O}$ fato da descoberta do tema letramento e os estudos referentes a ele também contribuíram demasiadamente para a diminuição do interesse nas técnicas de aprendizagem da escrita alfabética.

A Proposta Curricular do Estado de Santa Catarina, datada pelo ano de 2005, relata que a alfabetização estadual está alicerçada em duas teorias: Histórico-cultural, elaborada por Vygotsky, e a Dialógica, idealizada por Bakthin. Ambas permitem que as pessoas pertencentes ao processo de ensino aprendizagem sejam agentes de seu próprio fazer pedagógico, entendo os desafios do educador alfabetizador na atualidade.

Vygotsky menciona que as crianças aprendem devido a interações sociais, além de ser extremamente fundamental ao professor observar os ambientes sociais de onde são originados os pensamentos delas. Dessa maneira haverá uma maior compreensão do desenvolvimento cognitivo das mesmas. Lev Vygotsky ressalta a importância da mediação no processo de aprendizagem e acredita muitíssimo na possibilidade da criança aprender na troca de idéia com seus colegas, amigos, pais etc.

Bakthin vê três formas de "diálogos". Elas podem ser entre os objetos, do ser humano para com os objetos ou entre os indivíduos. A intenção de Bakthin é que haja indagações, respostas, isto é, comunicação. Na concepção dialógica o estudante interage com seus colegas e professor, mostrando-se um sujeito participativo, o qual está interessado no que é exposto, facilitando sua compreensão e aquisição de saberes. 
A partir dessas teorias, todas as distintas culturas, variações lingüísticas e situações sociais do estudante devem ser consideradas na elaboração da prática docente.

As classes de alfabetização formam-se necessariamente com um conjunto de alunos com histórias de vida diferentes, sendo, pelas contingências práticas, classes heterogêneas. Uns sabem algumas coisas, outros sabem outras; alguns já aprenderam algumas coisas próprias da escola, outros não. Algumas crianças tiveram pré-escola e aprenderam os rudimentos da leitura e da escrita, outras nunca estudaram nada. Algumas crianças aprendem coisas em casa, têm lápis, papel, livros, outros nunca tiveram nada disso. Cada aluno tem uma história (CAGLIARI, 2004: 52-3).

Tal heterogeneidade é, devido à concepção histórico-cultural da Proposta Curricular catarinense, algo relevantemente importante, pois:

[...] a heterogeneidade, característica presente em qualquer grupo humano, passa a ser vista como fator imprescindível para as interações na sala de aula. Os diferentes ritmos, comportamentos, e experiências, trajetórias pessoais, contextos familiares, valores e níveis de conhecimento de cada criança (e do professor) imprimem ao cotidiano Escolar a possibilidade de troca de repertórios de visão de mundo, confrontos, ajuda mútua e conseqüente ampliação das capacidades individuais (REGO, 1995, p. 88, in: P. C. 1998: 37).

O aluno, dessa maneira, não é visto como um sujeito passivo cujo aprendizado somente vem por transmissão do professor. Pelo contrário, o aluno é ativo, suas interações, realidades e conhecimentos prévios são os estopins para que se elaborem os conhecimentos a serem abordados em sala de aula, proporcionando, por meio de mediações provindas do educador, as condições necessárias para o alcance da internalização, ou seja, da plena assimilação do conteúdo trabalhado.

Há certamente enorme valia na Proposta Curricular de Santa Catarina, além de aparentar ser o melhor caminho para chegar ao êxito no quesito alfabetização, porém a problemática encontra-se no cotidiano das unidades de ensino públicas estaduais catarinenses, cujos procedimentos didáticos e pedagógicos, inúmeras vezes, fogem do padronizado no documento citado, todavia também podem alcançar bons resultados. Um exemplo claro apresenta-se em uma Escola de Educação Básica de vínculo estadual, situada no município de São Pedro de Alcântara. Isso porque, após verificar o PPP (Projeto Político Pedagógico), observar a prática de educadoras de classes de alfabetização e questioná-las sobre seus embasamentos teóricos para a elaboração de suas aulas, observou-se a ausência do pregado na Proposta de currículo e, assim mesmo, ocorre um bom processo de alfabetização.

Analisando o Projeto Político Pedagógico da Unidade, pôde-se evidenciar a falta de uma fundamentação teórica própria que venha a reger a prática docente, isto é, não há uma concepção, seja baseada em Piaget, Vygotsky ou quaisquer outros estudiosos, expressa na documentação escolar. Assim como também não se estabelece nenhum método didático. Logo, nem há uma teoria 
particular da escola, nem se determina o uso da fundamentação estabelecida na Proposta Curricular de SC.

Em diálogo com as professoras das classes de alfabetização, apreciaram-se pensamentos a respeito de alfabetizar. Para elas, de forma geral, o processo de ensinar a ler e escrever é oportunizar a inserção na sociedade, ofertando condições para saber questionar, interpretar e participar ativamente do meio no qual se encontra. Desse modo, torna-se algo importantíssimo e que ocorre em momentos distintos para cada criança, pois umas têm mais facilidade e rapidamente aprendem, enquanto outras demoram mais, ou seja, depende muito do desenvolvimento do próprio aluno.

As educadoras em questão, segundo as próprias, não seguem uma específica fundamentação teórica para suas atividades e planejamentos. Contudo, em aspecto amplo, ressaltam o método tradicional, informando serem ecléticas, visto que não estão sempre fixas ao tradicionalismo. O trabalho delas é alicerçado em cartilhas e ensinam da letra para a sílaba, da sílaba para a palavra, chegando à leitura e à escrita. Não há muito espaço para socializações e interações entre os alunos. Pouco se leva em conta a realidade da criança, pois as aulas já estão prontas, não sendo mudadas conforme interesses dos estudantes. Portanto, relacionando-as com um dos métodos de alfabetizar, elas estão no modelo sintético. Tanto que, como fotocópia em anexo, primeiro ensinam as letras simples, em seguida a "família" da mesma, formando as sílabas, chegando aos textos com palavras de sílabas simples. Há bastante enfoque nas datas comemorativas, na disciplina e no respeito em sala. A disposição dos educandos em sala é em filas, sendo um atrás do outro.

A direção e o corpo docente em sua grande maioria fazem uso de estratégias tradicionais. Um bom exemplo refere-se ao início de cada turno, pois os estudantes fazem filas no pátio e rezam uma oração denominada "Oração pelo Brasil”. Além de, uma vez por semana, cantarem o Hino Nacional ou o Hino à Bandeira. A escola é conhecida por cidades vizinhas como uma instituição disciplinadora em que o ensino ainda ocorre conforme os modelos mais antigos e em cuja efetivação de alfabetização e de aprendizagem realmente acontece. Assim, e por diversos outros fatores, pode-se considerar a escola uma unidade bem tradicional em seu método de ensino e de educação.

Portanto, diante do exposto, comprova-se a desvinculação, ou melhor, a falta de relação entre a Proposta Curricular de Santa Catarina e a escola estadual analisada. 


\section{CONSIDERAÇÕES FINAIS}

Analisando um dos conceitos de alfabetização, a evolução dos métodos de lecionar, as fundamentações teóricas da Proposta Curricular de Santa Catarina (2005) e a realidade de uma escola estadual em São Pedro de Alcântara pôde-se identificar ideias, situações diferentes, mas que também chegam ao mesmo objetivo: promover o aprendizado, a alfabetização.

Destaca-se como algo interessante a talvez "autonomia" que as unidades de ensino e professores têm, pois mesmo havendo uma diretriz curricular estadual a ser teoricamente seguida, não é o que ocorre efetivamente. Na realidade existe um distanciamento bastante acentuado entre a teoria e a prática, uma vez que ainda praticasse o método de ensino tradicional, apesar de documentalmente ser exposto o enfoque para o modelo Histórico-cultural de Vygotsky e a Dialógica de Bakthin.

Portanto, para que haja maior ligação entre a Proposta Estadual e as instituições educacionais estaduais, deve-se buscar padronizar mais as linhas de pensamentos e de embasamentos teóricos. Fornecer subsídios para que os educadores possam conhecer as fundamentações atuais e possam observar outras maneiras, além da tradicional, para alcançar um pleno processo de ensino aprendizagem. Não esquecendo jamais que o principal encontra-se na possibilidade de inserir a criança no mundo, sendo um ser com todas as habilidades necessárias, de leitura e escrita, para compreender e participar ativamente.

\section{REFERÊNCIAS}

CAGLIARI, Luiz Carlos. Alfabetizando sem ba-bé, bi, bó, bu. São Paulo: Ed. SCIPIONE, 1998.

FERREIRO, E. Matéria Alfabetização e Cultura Escrita. Nova Escola. São Paulo, Abril, maio de 2003. p. 27-30.

PEREIRA, Eliane Regina; CLEMENS, Juçara. Psicologia Geral e do Desenvolvimento. Indaial: Ed. ASSELVI, 2009.

Projeto Político Pedagógico da Escola de Educação Básica alicerce da pesquisa. 
REGO, Teresa Cristina. Vygostky - uma perspectiva histórico-cultural da educação. Petrópolis: Ed. VOZES, 1999.

Santa Catarina, Secretaria de Estado da Educação, Ciência e Tecnologia. Proposta Curricular de Santa Catarina: Estudos Temáticos. Florianópolis: IOESC, 2005.

SCHIOCHETTI, Neuzi Schotten. Fundamentos e Metodologia da Alfabetização. Indaial: Ed. Grupo UNIASSELVI, 2006.

SOARES, Magda. Letramento. Belo Horizonte: Ed. AUTÊNTICA, 1998.

TAFNER, Elisabeth Penzlien; SILVA, Everaldo da. Metodologia do Trabalho Acadêmico. Indaial: Ed. Grupo UNIASSELVI, 2008

\section{ANEXOS}

\section{Questionário dado às professoras:}

1- O que é alfabetizar para você?

2- Que método de ensino aprendizagem você utiliza para alfabetizar seus alunos?

3- A escola em que você leciona possui alguma teoria ou método que fundamenta sua prática docente?

4- Como é escolhido, planejado o conteúdo que você leciona?

5- Descreva brevemente como é uma aula de alfabetização sua? Como você ensina a letra, as sílabas etc? 
6- Como você procede para verificar se seu aluno está aprendendo a ler e escrever?

Exemplo de Seqüência de Atividades Trabalhadas sobre a letra T: 


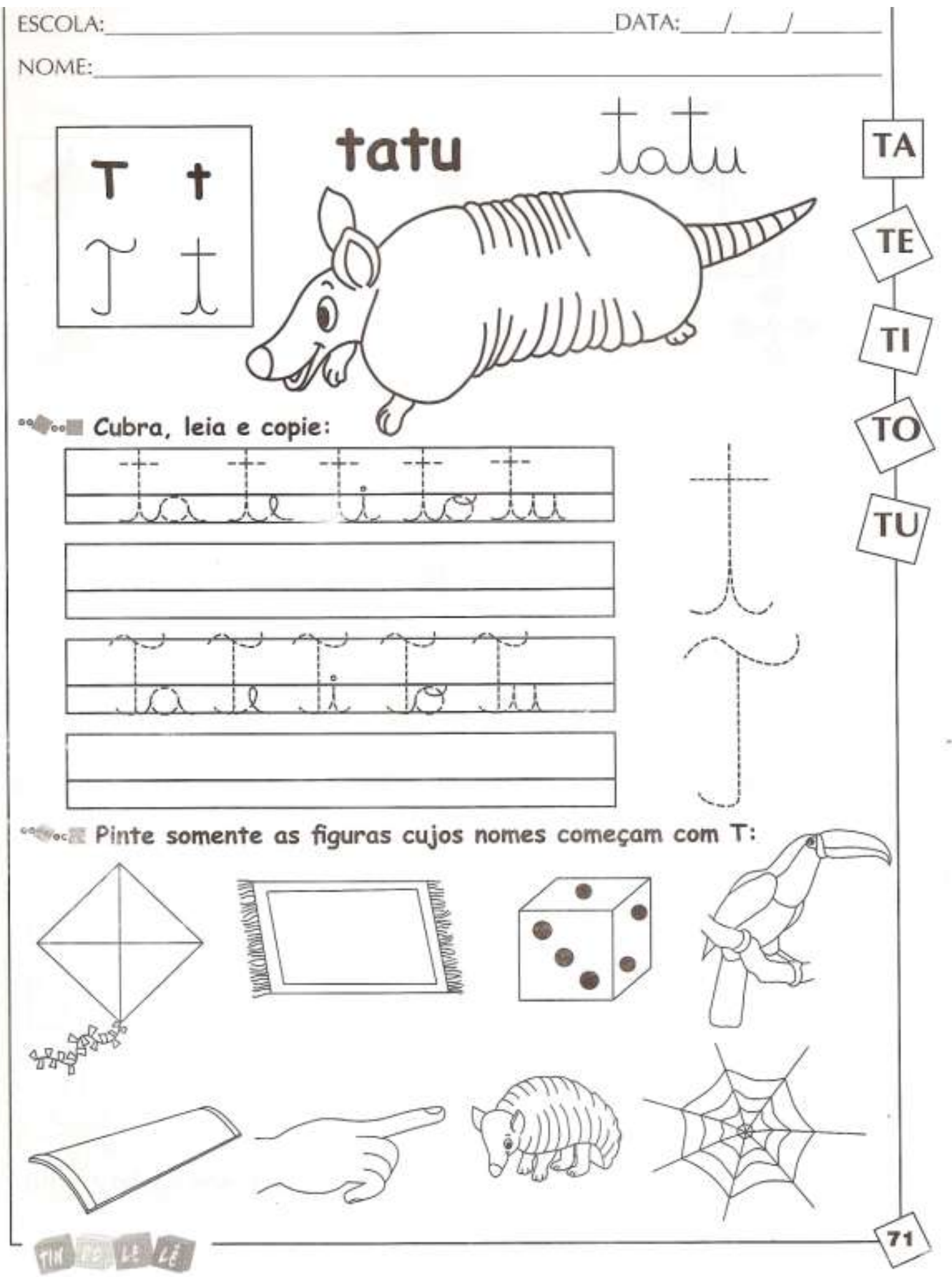




\section{ESCREVENDO PALAVRAS COM T}

SIGA AS SETAS E FORME PALAVRAS! JÁ COMECEI!

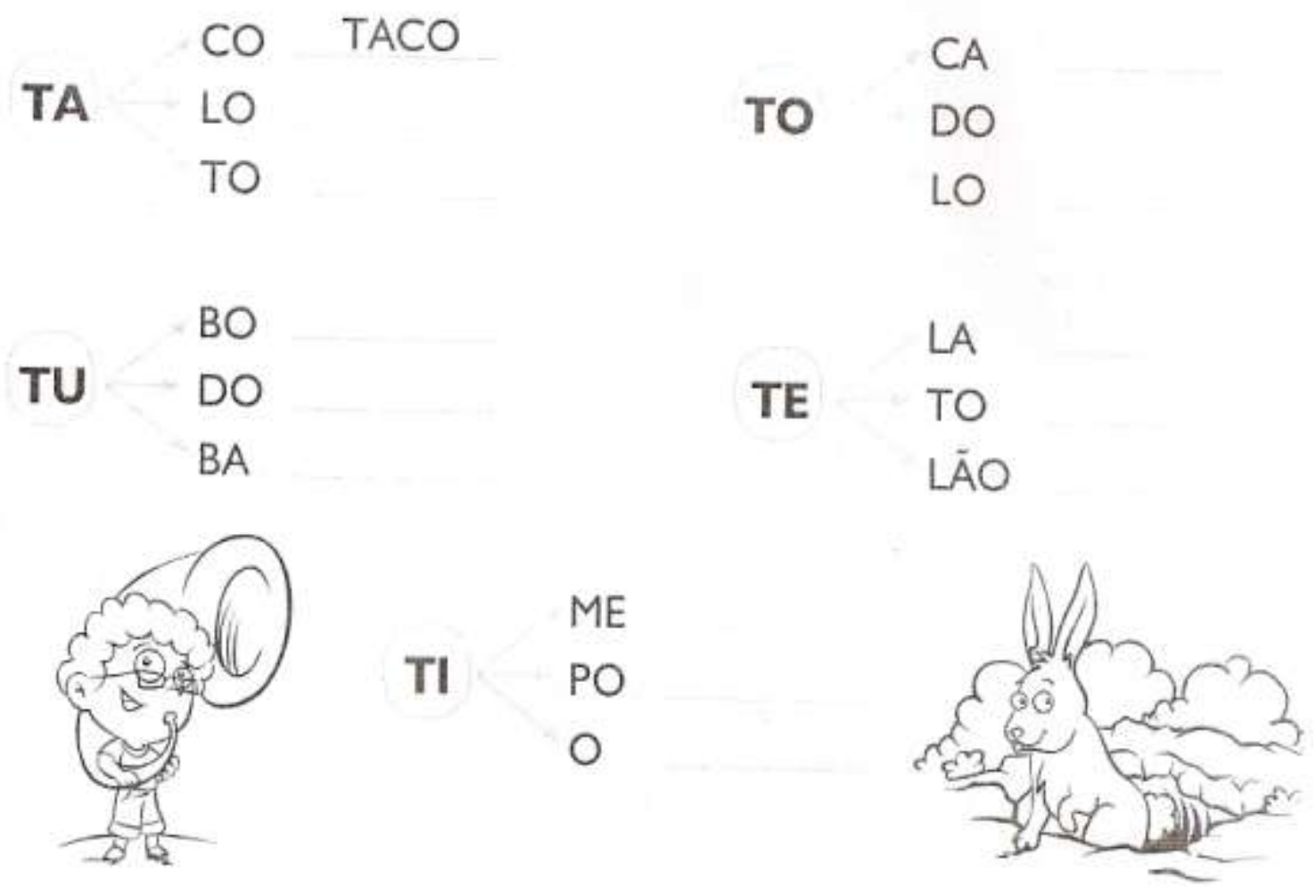

PINTE A PALAVRA CORRESPONDENTE A CADA DESENHO E, DEPOIS, ESCREVA-A NO ESPAÇO ABAIXO.

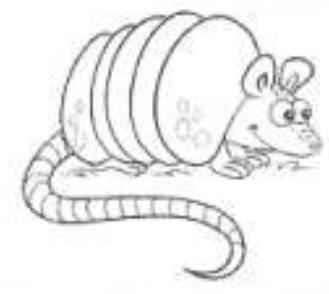

TACO TATU

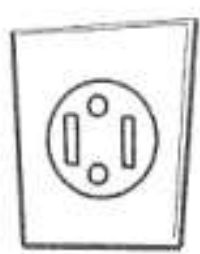

POMADA TOMADA

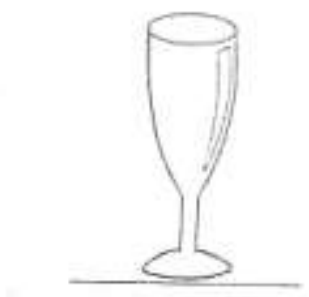

TAÇA TOCA 


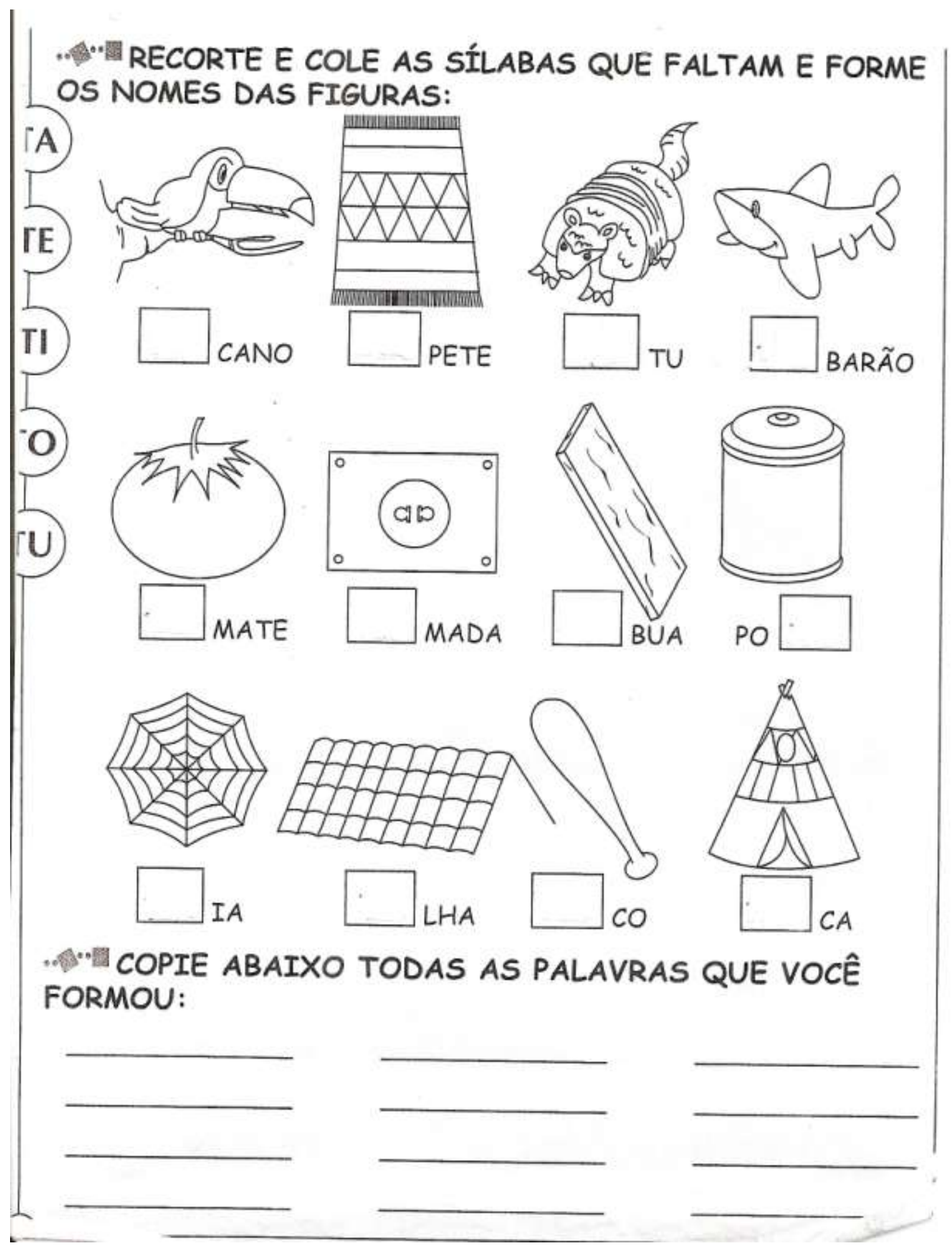


ESCOLA:

DATA:

NOME:

\section{VAMOS BRINCAR?}

TA Pinte todas as letras $T$ que você encontrar no texto abaixo:

TE
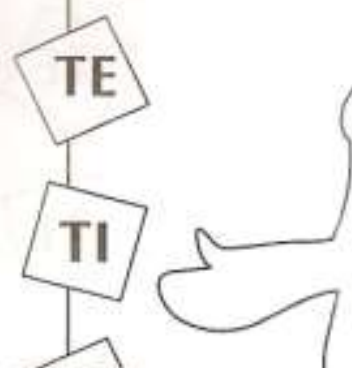

TO

TU

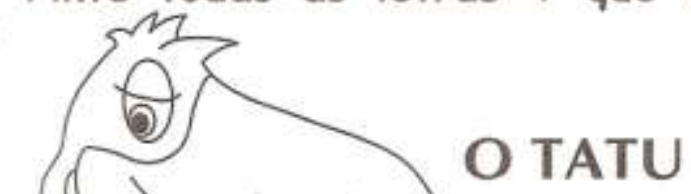

7 (

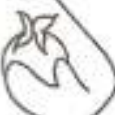

O TATU TOCA O APITO,

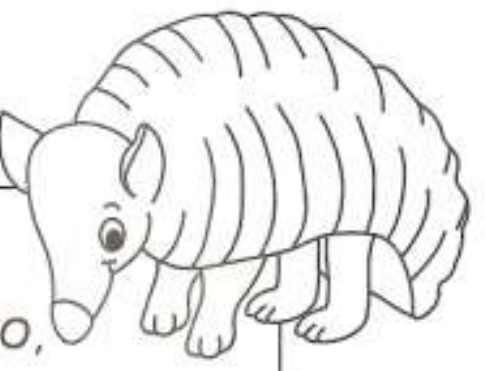

NO JOGO DO TIME DA TITIA.

LÁNA MATA,

O TUCANO COME TOMATE

E TORCE PARA O TIME DO TATU.

O TIME GANHA E O TATU TOCA TUBA NA MATA

E AÍ PULA PULA...

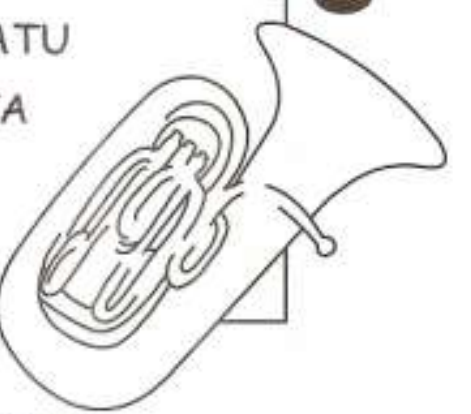

$\because$ ooll Encaixe as palavras nos tapetinhos de letras:

APITO

BATATA

TIME

LATA

TUCANO

TOMATE

MATA

TITIA
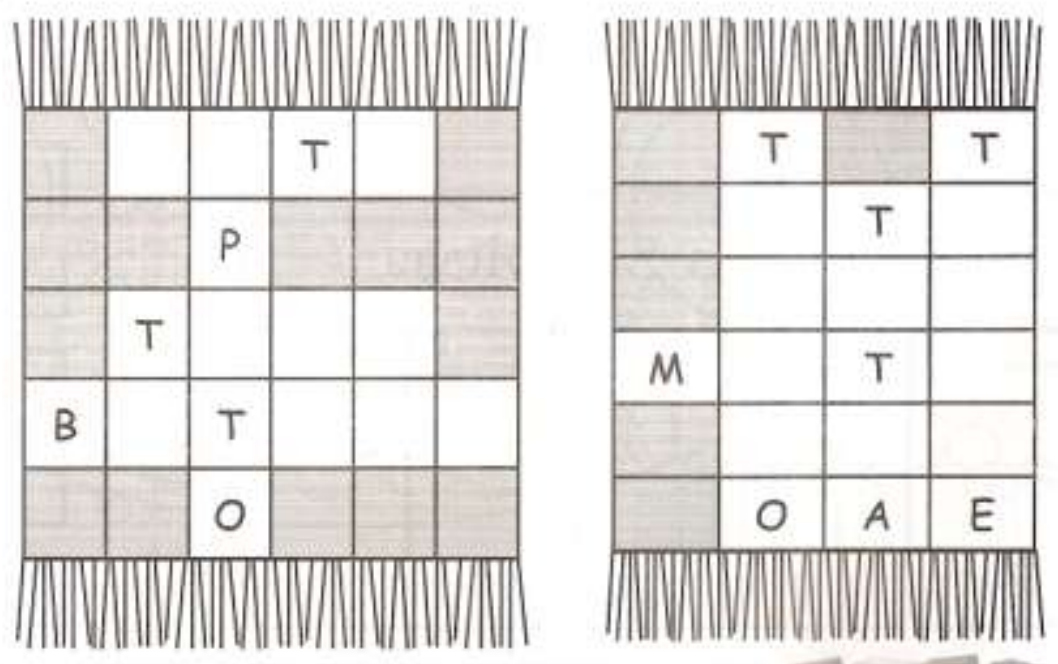


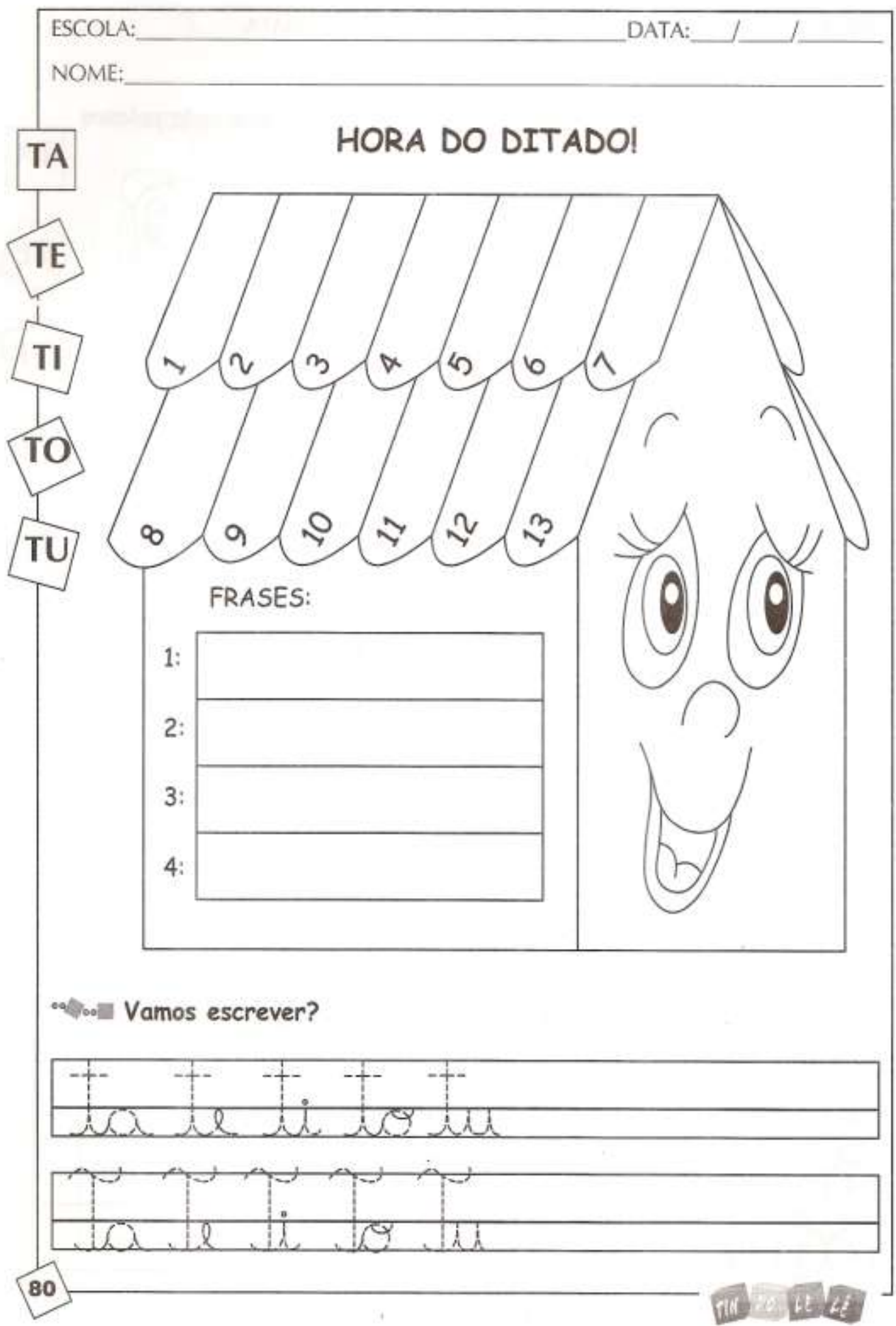

